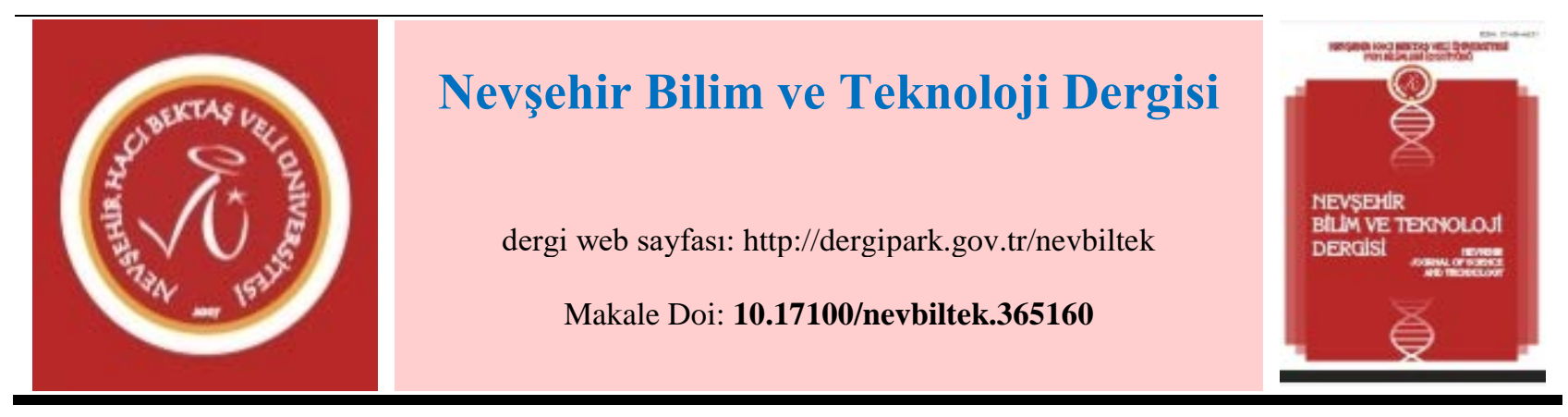

\title{
Fren Sürtünme Malzemelerinde Aşındırıcıların (Alümina, Silika, Zirkon) Tribolojik Özellikleri
}

\author{
Banu SUGÖZÜ ${ }^{1}$, Behcet DAĞHAN ${ }^{2}$ \\ ${ }^{1}$ Mersin Üniversitesi, Mühendislik Fakültesi, Makine Mühendisliği Bölümü, Mersin \\ ${ }^{2}$ Selçuk Üniversitesi, Mühendislik Fakültesi, Makine Mühendisliği Bölümü, Konya
}

Öz

Otomotiv fren sürtünme malzemeleri, fiberler (takviye elemanları), yapıştıııı, katı yağlayıcılar, sürtünme düzenleyiciler, aşındırıcılar ve dolgu malzemelerinden oluşan çok bileşenli kompozitlerdir. Aşındırıcılar daha yüksek Mohs sertliğine sahip malzemelerdir ve fren sürtünme malzemelerinin tribolojik özelliklerinde önemli rol oynarlar. Ticari fren sürtünme malzemelerinde en yaygın kullanılan aşındırıcılar, alümina $\left.\left(\mathrm{Al}_{2} \mathrm{O}_{3}\right), \mathrm{silika}_{(\mathrm{SiO}}\right)$, silisyum karbür ( $\mathrm{SiC})$, zirkon $\left(\mathrm{ZrSiO}_{4}\right)$ ve zirkonya $\left(\mathrm{ZrO}_{2}\right)$ dır. Bu çalışmada alümina, silika ve zirkon (kütlece \%5 ve \%10) olmak üzere üç farklı aşındırıcı kullanılarak altı fren balata numunesi üretilmiş ve sürtünme özellikleri araştırılmıştır. Numuneler sırayla toz karıştırma, ön şekillendirme ve sıcak presleme işlemlerini kapsayan geleneksel yöntemle üretilmiştir. Numunelerin sürtünme ve aşınma karakteristikleri pad-on-disk tipi aşınma test cihazı kullanılarak belirlenmiştir. Numunelerin sertlik, yoğunluk, porozite, çekme dayanımı, basma dayanımı gibi fiziksel ve mekanik özellikleri ve Taramalı Elektron Mikroskobuna (SEM) yardımıyla morfolojik özellikleri incelenmiştir. Sonuç olarak aşındırıcı miktarındaki artış sürtünme katsayısını arttırmış, özgül aşınma oranını ise azaltmıştır. Kütlece \%10 alümina içeren numune daha iyi bir sürtünme performansı sergilemiştir.

Anahtar Kelimeler: Aşındırıcılar, Fren balatası, Aşınma, Sürtünme, Triboloji.

\section{Tribological Properties of Abrasives (Alumina, Silica, Zircon) for Brake Friction Materials}

\begin{abstract}
Automotive brake friction materials are multi-component composites composed of functional materials such as fibers (reinforcements), binder, solid lubricants, friction modifiers, abrasives and space fillers. Abrasives are the ingredients that have higher Mohs hardness and play important roles on tribological properties of brake friction materials. Most commonly used abrasives in commercial brake friction materials are alumina $\left(\mathrm{Al}_{2} \mathrm{O}_{3}\right)$, silica $\left(\mathrm{SiO}_{2}\right)$, silicon carbide $(\mathrm{SiC})$, zircon $\left(\mathrm{ZrSiO}_{4}\right)$ and zirconia $\left(\mathrm{ZrO}_{2}\right)$. In this study, six brake lining samples were produced using abrasives of three types viz. silica, alumina and zircon (5 and $10 \mathrm{wt} . \%$ ) and investigated its friction properties. The samples were produced by a conventional procedure for a dry formulation following dry-mixing, pre-forming and hot pressing. Friction and wear characteristics of the specimens were examined using a pad-ondisc-type wear tester. The physical and mechanical properties such as hardness, density, porosity, tensile strength, compressive strength of samples and morphological properties via Scanning Electron Microscope (SEM) were investigated. The results of tests showed that the friction coefficients of the composites increased with increasing abrasive amount. The results also indicated that specific wear ratio of the composites decreased with increasing abrasive amount. The sample containing $10 \mathrm{wt}$ \% alumina exhibited the better friction performance.
\end{abstract}

Keywords:Abrasives, Brake lining, Wear, Friction, Tribology.

1e-mail: banusugozu@mersin.edu.tr 


\section{Giriş}

Taşıtların fren sistemlerinde yer alan disk ve balata kompozitlerinin sürtünme ve aşınma özelliklerini inceleyen birçok çalışma yapılmıştır. Taşıtlarda fren balataları, çeşitli fonksiyonlara sahip birçok malzemenin bir araya gelmesiyle oluşan kompozit malzemelerdir. Balata kompozitlerinde yapıştırıcı olarak fenolik reçine, sentetik reçine, takviye elemanı olarak çelik yünü, cam elyaf, aramid (kevlar), bor elyaf, katı yağlayıcı olarak grafit, antimonit, sürtünme düzenleyici olarak metalik talaşlar, maun cevizi tozu, aşındırıcı olarak alümina, silika, zirkon, silisyum karbür, kuvars, dolgu malzemesi olarak ise barit, kalsiyum karbonat ve vermikülit gibi malzemeler kullanılır. Kompoziti oluşturan her bir malzemenin çeşidi ve miktarının yanı sıra üretim aşamasında kullanılan parametreler de balatanın tribolojik özelliklerini önemli derecede etkilemektedir. Bu sebeple fren balatalarının performans gereklilikleri oldukça karmaşıktır.

Literatürde fren balata malzemelerinden aşındırıcıları inceleyen çalışmalar mevcuttur. Bijwe ve arkadaşları [1], aşındırıcı olarak alümina, silika ve silisyum karbür içeren mikro ve nanokompozitler tasarlayarak tribolojik performansının yanı sıra çeşitli kimyasal ve fiziksel özelliklerini incelemişlerdir. Kim ve arkadaşları [2], farklı aşınma partikülleri içeren otomotiv fren balatalarının sürtünme ve titreşimini inceledikleri çalışmalarında aşındırıcıların frenleme esnasında oluşan gürültü ve titreşimin yanında sürtünme seviyesi ve aşınarak kopan partiküllerin oluşumunda önemli rol oynadığını belirtmişlerdir. Shin ve arkadaşları [3], fren sürtünme malzemelerinin sürtünme etkinliği ve kararlılı̆̆ üzerinde aşındırıcı boyutunun etkisini farklı boyutlarda zirkon ekledikleri numuneler ile araştırmışlar ve aşındırıcı boyutuyla sürtünme özellikleri arasında doğrudan ilişki olduğu sonucuna varmışlardır. Benzer bir çalışmada Ma ve arkadaşları [4], metalik olmayan fren sürtünme malzemelerinin sürtünme performansında zirkonun etkilerini incelemişler ve zirkonun sürtünme katsayısını arttırdığını, aşınma oranını ise düşürdüğünü gözlemlemişlerdir. Boz ve Kurt [5] ise farklı oranlarda kullandıkları alüminanın sürtünme ve aşınma üzerinde etkilerini incelerken alümina miktarındaki artışın kütle kaybında düşüşe neden olduğunu öne sürmüşlerdir.

Bu çalışmada balata kompozisyonu içerisinde aşındırıcı fonksiyonu olan silika, alümina ve zirkon (kütlece \%5 ve \%10) kullanılarak 6 adet farklı içerikli balata numunesi üretilerek fiziksel ve tribolojik özellikleri araştırılmıştır.

\section{Materyal ve Metot}

Üretilen numunelerin içerikleri ve üretim parametreleri belirlenirken literatürden ve bu çalışma için gerçekleştirilen ön çalışmalardan faydalanılmıştır. Kullanılan malzemelerin \% kütlesel miktarları Tablo 1'de gösterilmiştir. A5, A10, S5, S10, Z5 ve Z10 numunelere verilen isimlerdir. Harf, aşındırıcının cinsini (alümina için A, silika için S, zirkon için Z), sayı ise kompozit içindeki kütlesel yüzdesini belirtir.

Tablo 1. Balata numunelerinde kullanılan malzemelerin miktarları (\% kütl
\begin{tabular}{llllllll}
\multicolumn{7}{l}{ Miktar (\% kütlesel) } \\
\cline { 2 - 7 } Malzeme & A5 & A10 & S5 & S10 & Z5 & Z10 \\
\hline Reçine & 22 & 22 & 22 & 22 & 22 & 22 \\
Çelik yünü & 15 & 15 & 15 & 15 & 15 & 15 \\
Maun cevizi tozu & 10 & 10 & 10 & 10 & 10 & 10 \\
Pirinç talaşı & 5 & 5 & 5 & 5 & 5 & 5 \\
Grafit & 3 & 3 & 3 & 3 & 3 & 3 \\
Bakir talaşı & 8 & 8 & 8 & 8 & 8 & 8 \\
Barit & 32 & 27 & 32 & 27 & 32 & 27 \\
Alümina & 5 & 10 & - & - & - & - \\
Silika & - & - & 5 & 10 & - & - \\
Zirkon & - & - & - & - & 5 & 10 \\
\hline
\end{tabular}

Balatayı oluşturan her bir malzemenin balata üzerinde bir fonksiyonu vardır. Bu çalışmada kullanılan malzemelerin fonksiyonları Tablo 2'de belirtilmiştir. 
Tablo 2. Balata numunelerinde kullanılan malzemelerin fonksiyonları

\begin{tabular}{ll}
\hline Malzeme & Fonksiyon \\
\hline Reçine & Bağlayııı malzeme (yapıştırıcı) \\
Çelik yünü & Takviye malzemesi (elyaf) \\
Maun cevizi tozu & Sürtünme düzenleyici \\
Pirinç talaşı & Sürtünme düzenleyici \\
Grafit & Katı yağlayıcı \\
Bakır talaşı & Sürtünme düzenleyici \\
Barit & Dolgu malzemesi \\
Alümina & Aşındırıcı (Abrazif) \\
Silika & Aşındırıcı (Abrazif) \\
Zirkon & Aşındırıcı (Abrazif) \\
\hline
\end{tabular}

Otomotiv fren balatası, farklı özelliklere sahip malzemelerin toz haline getirilip preslenmesi ile oluşan kompozit bir malzemedir. Kimyasal ve mekanik özellikleri, içerdiği malzeme oranlarına göre değişmektedir. Bu yüzden bir balata malzemesi tasarımında, kompozisyonu oluşturan malzemelerin ve oranlarının tespiti oldukça önemli ve karmaşık bir konudur. Fren balatasının üretimi de en az kompozisyonu kadar özelliklerin tespitinde ve değişiminde rol oynar. Çünkü üretim esnasında malzeme özellikleri değişmekte ve kompozisyonlar aynı olsa bile farklı üretim parametreleri ile üretilen balatalar çok farklı özellikler sergileyebilmektedir [6].

Toz metalurjisi yöntemiyle üretilen numunelerin toz karıştırma, soğuk presleme ve sıcak presleme parametrelerinin rakamsal değerleri belirlenirken kullanılan malzeme özelliklerinden ve literatürden yararlanılarak bir dizi ön deneyler yapılmıştır. Buna göre üretilen numunelerin üretim parametreleri Tablo 3'de verilmiştir.

Tablo 3. Balata numunelerinin üretim parametreleri

\begin{tabular}{llll}
\hline & Süre $(\mathrm{dk})$ & Basınç $(\mathrm{kPa})$ & Sıcaklık $\left({ }^{\circ} \mathrm{C}\right)$ \\
\hline Karıştırma & 10 & - & - \\
Ön şekillendirme & 2 & 8000 & ortam sıcaklı̆̆ 1 \\
Sıcak presleme & 12 & 10000 & 150 \\
\hline
\end{tabular}

Numunelerin sertliği Brinell sertlik ölçme cihazıyla elde edilmiştir ve batıcı uç olarak çapı $2.5 \mathrm{~mm}$ olan çelik bilye uç kullanılmıştır. Uygulanan yük 62.5 kgf (612.9 N) olarak alınmıştır. Sertlik ölçümleri, numunelerin sürtünme testlerinde diske temas eden yüzeyinden elde edilmiştir. Numunelerin orta ve kenara yakın beş farklı noktasından değerler alınmış ve aritmetik ortalamaları hesaplanmıştır. Her test için aynı içerikli üç numune kullanılmıştır.

Üretilen numunelerin yoğunlukları, TS 555(Karayolu Taşıtları-Fren Sistemleri-Balatalar-Sürtünmeli Frenler İçin) [7] ve Arşimet prensibine göre hesaplanmıştır. Her ölçüm için aynı içerikli üç numune kullanılarak sonuçların aritmetik ortalaması alınmıştır. Numunelerin porozitesi ise, $3 \mathrm{~nm}$ ile $360 \mu \mathrm{m}$ aralığında iç gözenekleri ölçebilen (AutoPore IV 9500 V1.09, maksimum $292 \mathrm{MPa}$ ) civa porozimetresi ile ölçülmüştür.

Deneyler sırasında balatanın fren diskine sürtünmesi sonucunda sürtünme yüzeyi sıcaklığı artmaktadır. Sıcaklık artısııın sürtünme katsayısı üzerindeki etkisini incelemek amacıyla temassız (infrared) termometre ile balatanın diske sürtünme yüzeyinden yaklaşık $2 \mathrm{~cm}$ mesafeden diskin yüzey sıcaklığı ölçülmüştür. Sıcaklık ölçümünde her saniye veri alabilen dijital bir termometre kullanılmıştır. Cihaz sayesinde diskin yüzey sıcaklığı, deney süresince saniye olarak bilgisayar ortamına otomatik olarak aktarılmıştır.

Numunelerin aşınma ve sürtünme katsayısı gibi özelliklerini elde etmek amacıyla TS 555 [7] standardında atıf yapılan TS 9076'a (Karayolu Taşıtları-Fren Sistemleri-Fren Balataları-Malzeme Sürtünme Özelliklerinin Küçük Deney Parçaları ile Değerlendirilmesi) uygun [8] deneyler gerçekleştirilmiştir. Buna göre öncelikle 310 dev/dak, 700 kPa basınç ve sıcaklık $100{ }^{\circ} \mathrm{C}^{\prime} y i$ aşmayacak şekilde numunenin diske yüzey teması en az $\% 95$ oluncaya kadar alışırma işlemi yapılmıştır. Böylece yüzey, deneye hazır hale getirilmiştir. 


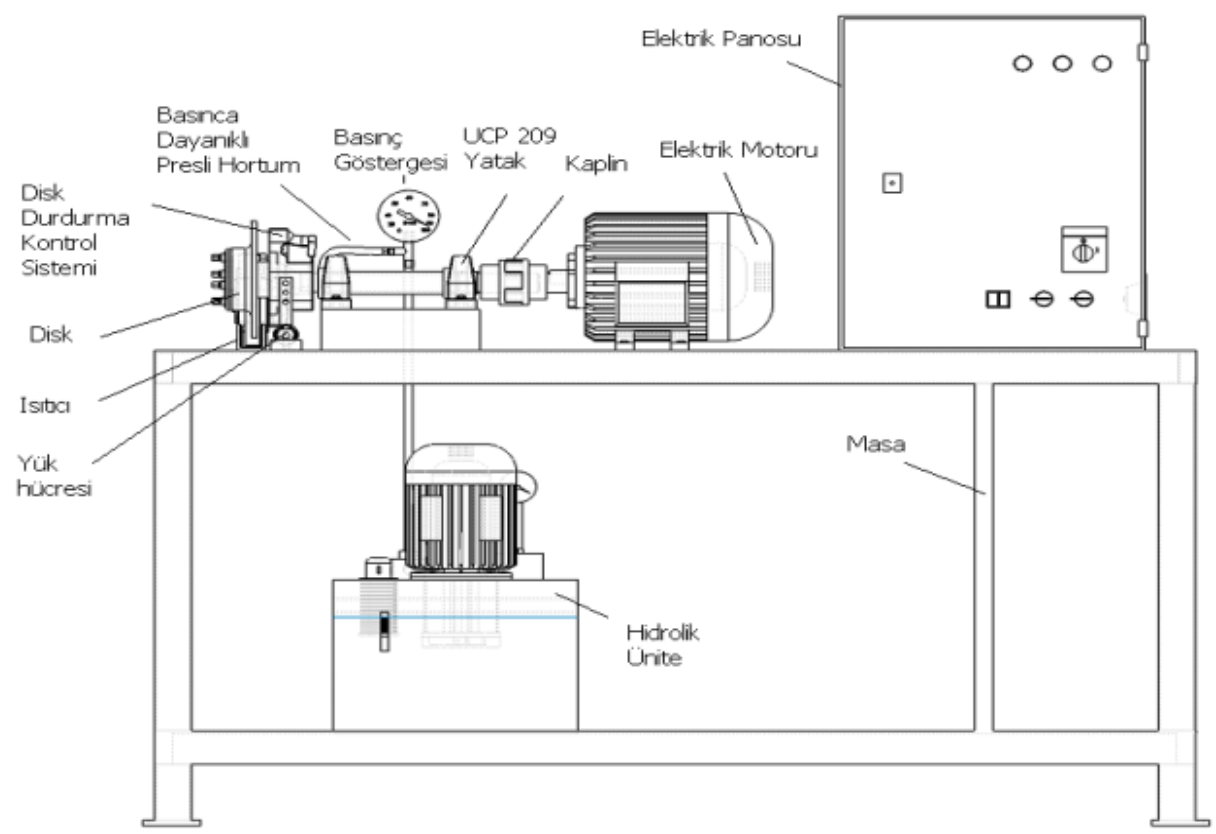

Şekil 1. Sürtünme test cihazının şematik çizimi [9]

Numuneler, çapı 280 mm ve sertliği 116 HB olan gri dökme demir diskin kullanıldığı, Şekil 1'de şematik çizimi verilen tam ölçekli bir fren balata cihazında test edilmiştir. Cihaz tamamen bilgisayarla kontrol edilebilir ve veri toplama yazılımı içermektedir.

\section{Bulgular}

Fren sürtünme malzemelerinin sürtünme katsayısı fren performansını etkileyen önemli bir parametredir ve durma mesafesi, gürültü eğilimi, feyd, fren kaynaklı titreşim gibi çeşitli fren olaylarını anlamak için kullanılabilir [10].

Numunelerin kayma mesafesine bağlı olarak sıcaklık ve sürtünme katsayısı değişimleri Şekil 2-7'de gösterilmiştir. Şekillerde, sürtünme katsayısının testin başlangıcında düşük olmasının sebebi, uygulanan basıncın ani olarak değil giderek artan şekilde etki etmesidir. Ani basınç uygulaması, balataların hasar görmesine neden olacağından basınç artışı kademeli olarak sağlanmıştır. Ayrıca testin başlangıcında balata ile disk alışma (rodaj) sürecindedir ve sürtünme kuvvetinin etkili olduğu sürtünme tabakaları henüz oluşmamıştır [11].

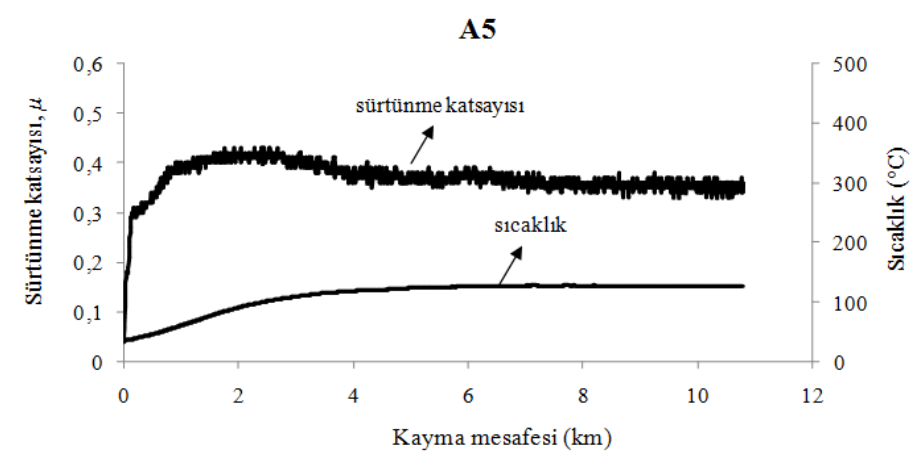

Şekil 2. Kütlece \%5 alümina içeren numunenin sürtünme katsayısı-kayma mesafesi-sıcaklık grafiğgi (basınç $1050 \mathrm{kPa}$, hız $6 \mathrm{~m} / \mathrm{s}$, süre $30 \mathrm{dk}$ ) 
Nevşehir Bilim ve Teknoloji Dergisi (2018), 7(1) 14-23

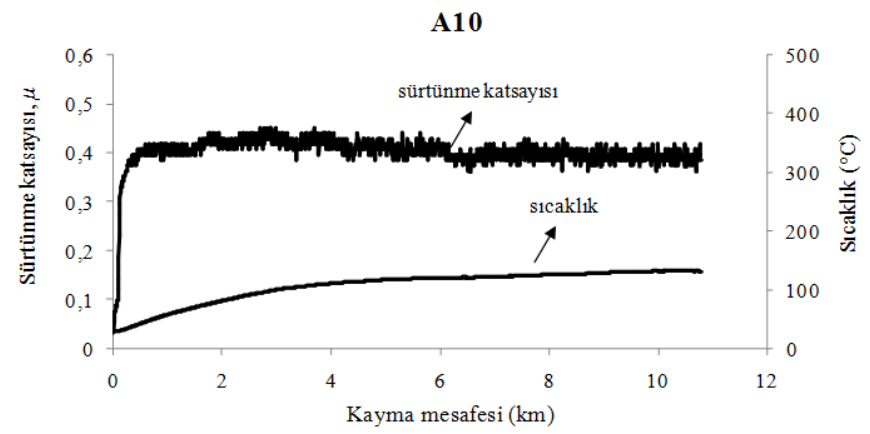

Şekil 3. Kütlece $\% 10$ alümina içeren numunenin sürtünme katsayısı-kayma mesafesi-sıcaklık grafiği (basınç $1050 \mathrm{kPa}$, hız $6 \mathrm{~m} / \mathrm{s}$, süre $30 \mathrm{dk}$ )

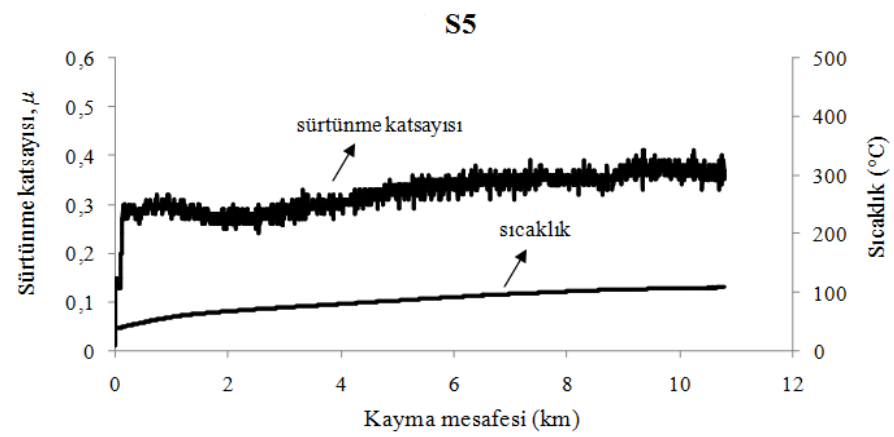

Şekil 4. Kütlece $\% 5$ silika içeren numunenin sürtünme katsayısı-kayma mesafesi-sıcaklık grafiği (basınç $1050 \mathrm{kPa}$, hız $6 \mathrm{~m} / \mathrm{s}$, süre $30 \mathrm{dk}$ )

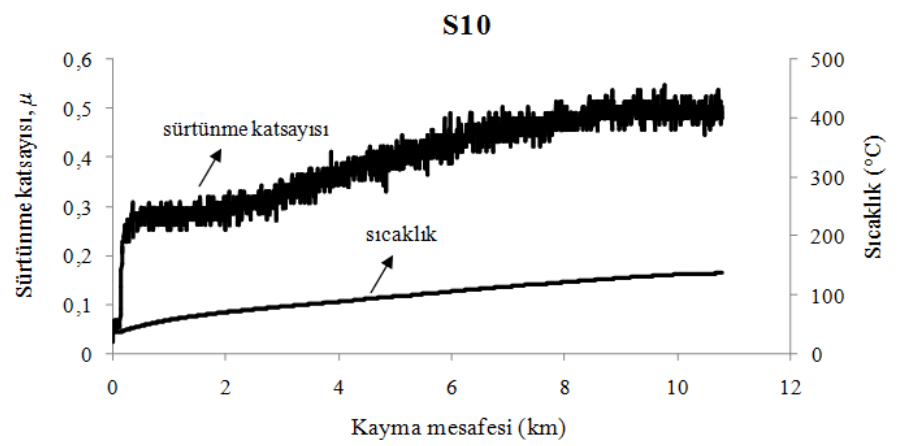

Şekil 5. Kütlece \%10 silika içeren numunenin sürtünme katsayısı-kayma mesafesi-sıcaklık grafiğgi (basınç $1050 \mathrm{kPa}$, hız $6 \mathrm{~m} / \mathrm{s}$, süre $30 \mathrm{dk}$ )

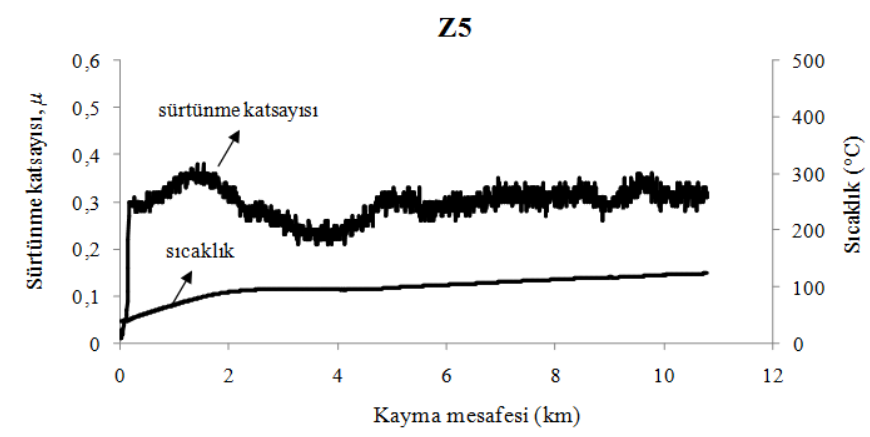

Şekil 6. Kütlece $\% 5$ zirkon içeren numunenin sürtünme katsayısı-kayma mesafesi-sıcaklık grafiği (basınç $1050 \mathrm{kPa}$, hız $6 \mathrm{~m} / \mathrm{s}$, süre $30 \mathrm{dk}$ ) 


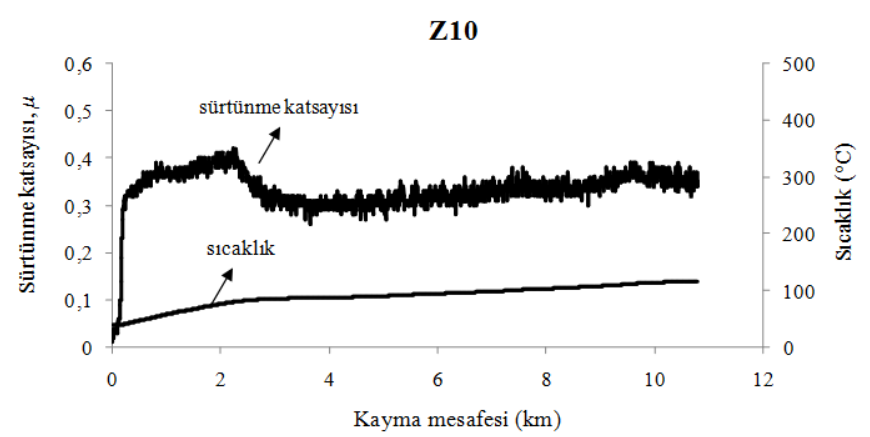

Şekil 7. Kütlece \%10 zirkon içeren numunenin sürtünme katsayısı-kayma mesafesi-sıcaklık grafiği (basınç $1050 \mathrm{kPa}$, hız $6 \mathrm{~m} / \mathrm{s}$, süre $30 \mathrm{dk}$ )

Fren balatalarından istenen en önemli özelliklerden biri frenleme esnasında sürtünmeden dolayı açığa çıkan ara yüzey sıcaklığındaki artışa bağlı olarak sürtünme katsayısındaki değişimin minimum seviyede olmasıdır [12,13]. Literatürde sürtünme katsayısının, sürtünme kuvveti ve disk-balata ara yüzey sıcaklığına bağlı olarak 0.1 ila 0.7 arasında değiştiği vurgulanmıştır [14].

Grafikler incelendiğinde sürtünme katsayısında az miktarda olsa da inişli çıkışlı sürekli bir değiş̧im görülmektedir. Anderson [15] bunun sebebini, sürtünme süresince disk yüzeyindeki temas bölgelerinin içine doğru 1sının periyodik olarak sürekli değişmesinden kaynaklandığını belirtmiş̧tir. Bu etkiden dolayı sürtünme katsayısında sürekli bir değişim meydana gelmektedir. Ayrıca bu durumu Stachowiak ve Batchelor [16] sürtünme çiftlerinin yüzeyindeki pürüzlerde birleşme olması ve büyümesi ile açıklamaktadır. Bu durumda bir yapışma bir bırakma hali sürekli tekrarlanmakta, bu da sürtünme katsayısında sürekli artma ve azalmaya neden olmaktadır.

Numunelerin porozite, yoğunluk ve sertlik gibi fiziksel özellikleri Tablo 4'de gösterilmiştir. Porozitenin en önemli avantajı ses ve vibrasyonu (titreşimi) sönümlemesidir fakat porozite malzeme içerisinde yalıtkan görevi görmekte ve malzemenin sürtünmeden kaynaklanan sıcaklığını uzaklaştırmaya engel olmaktadır. Sasaki [17]'e göre sürtünme malzemelerinin gürültü eğilimi göz önüne alınırsa porozitenin yüksek sıcaklıklarda yeterince mukavemet sağlayacak kadar bir değerde olması gerekmektedir.

Tablo 4. Balata numunelerinin fiziksel özellikleri

\begin{tabular}{llll}
\hline $\begin{array}{l}\text { Numune } \\
\text { Kodu }\end{array}$ & $\begin{array}{l}\text { Porozite } \\
(\%)\end{array}$ & $\begin{array}{l}\text { Yoğunluk } \\
\left(\mathrm{g} / \mathrm{cm}^{3}\right)\end{array}$ & $\begin{array}{l}\text { Sertlik } \\
(\mathrm{HB})\end{array}$ \\
\hline A5 & 9.26 & 2.081 & 23.5 \\
A10 & 9.14 & 2.188 & 30.6 \\
S5 & 12.09 & 1.941 & 18.9 \\
S10 & 9.33 & 2.024 & 20.4 \\
Z5 & 6.83 & 2.163 & 31.3 \\
Z10 & 5.91 & 2.237 & 32.5 \\
\hline
\end{tabular}

Balatayı oluşturan malzemelerin fonksiyonları arasında aşındırıcı (abrazif) olarak kullanılan malzemelerin sertliği, balata kompozisyonu içerisinde bulunan diğer malzemelerden daha yüksektir [18]. Sertliği yüksek olan malzemelerin balata içerisinde yer alması ise sürtünme testi esnasında balata yüzeyinde sürtünme tabakası oluşturmakta ve balataların sürtünme katsayısını arttırmaktadır. Tablo 4 incelendiğinde aşındırıcıların kendi aralarında grup olduğu düşünülürse, aşındırıcı miktarındaki artışın sertlik ve yoğunluğu arttırdığı poroziteyi ise azalttığı görülmektedir. Fren sürtünme malzemelerinde sertliğin sürtünme katsayısını etkilediği bilinmektedir. Sertlik sürtünme katsayısıyla doğru orantılıdır fakat karşı malzemeyi (diski) aşındırmayacak değerde olmalıdır. Tablo 5'de numunelerin aşınma-sürtünme testlerinden elde edilen tribolojik özellikleri gösterilmiştir. 
Nevşehir Bilim ve Teknoloji Dergisi (2018), 7(1) 14-23

Tablo 5. Balata numunelerinin tribolojik özellikleri

\begin{tabular}{llll}
\hline $\begin{array}{l}\text { Numune } \\
\text { Kodu }\end{array}$ & $\begin{array}{l}\text { Özgül aşınma } \\
\text { oranı }\left(\mathrm{cm}^{3} / \mathrm{Nm}\right)\end{array}$ & $\begin{array}{l}\text { Ortalama sürtünme } \\
\text { katsayıs }\end{array}$ & $\begin{array}{l}\text { Balata } \\
\text { sinıfi }\end{array}$ \\
\hline A5 & $0.216 \times 10^{-6}$ & 0.367 & $\mathrm{~F}$ \\
A10 & $0.193 \times 10^{-6}$ & 0.407 & $\mathrm{~F}$ \\
S5 & $0.383 \times 10^{-6}$ & 0.364 & $\mathrm{~F}$ \\
S10 & $0.339 \times 10^{-6}$ & 0.405 & $\mathrm{~F}$ \\
Z5 & $0.239 \times 10^{-6}$ & 0.296 & $\mathrm{E}$ \\
Z10 & $0.196 \times 10^{-6}$ & 0.332 & $\mathrm{E}$ \\
\hline
\end{tabular}

TS 555'e göre [7] balatalar sürtünme katsayılarına göre;

$0.25-0.34(\mathrm{E})$,

$0.35-0.44(F)$,

$0.45-0.54(G)$,

0.55 ve yukarısı $(\mathrm{H})$ olarak sinıflandırılır.

Balataların özgül aşınma miktarının ortalama sürtünme kuvveti ve balata yoğunluğuna bağlı olduğu bilinmektedir. Sürtünme-aşınma testlerinden elde edilen sonuçların literatüre yakın ve TS 555'e uygun olduğu görülmüştür.
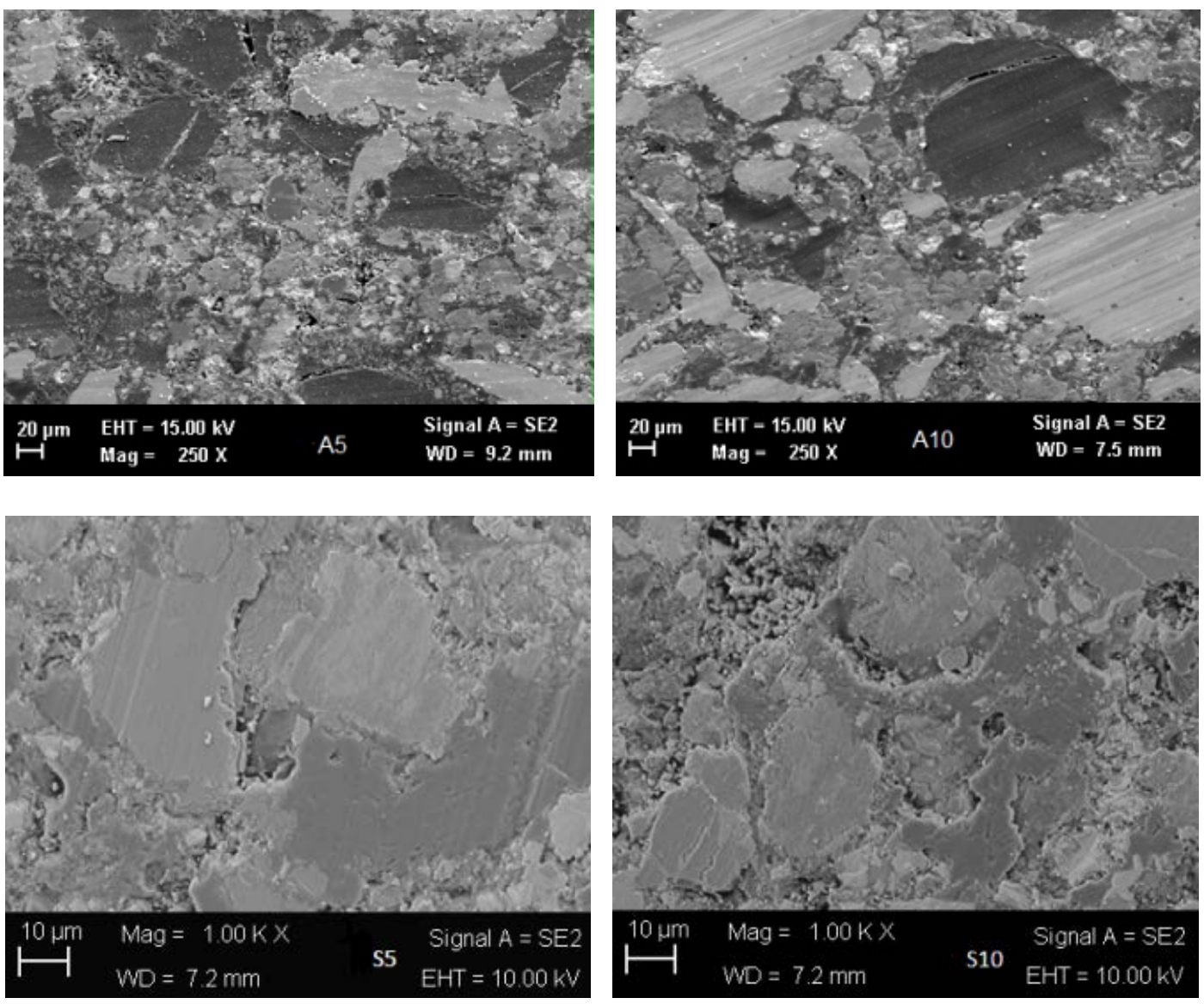

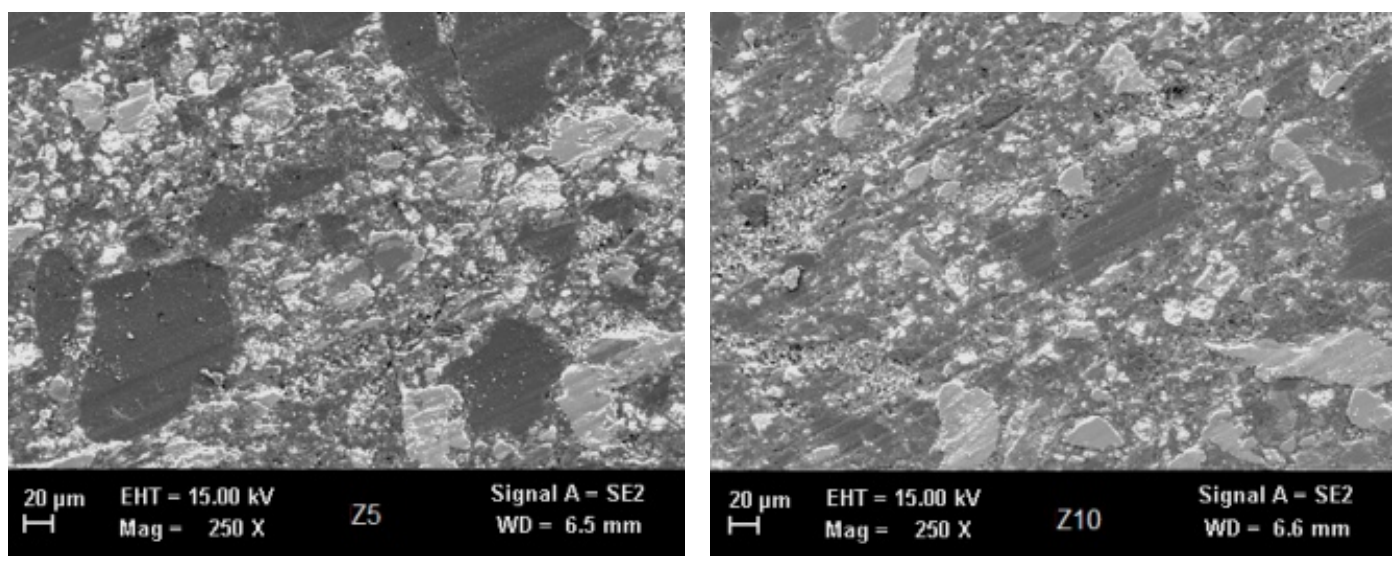

Şekil 8. Numunelerin SEM resimleri

Sürtünme testinden sonra numunelerin yüzeyi taramalı elektron mikroskobu (SEM) kullanılarak analiz edilmiştir. Şekil 8'deki resimler incelendiğinde numunelerin yüzeylerinde meydana gelen sürtünme tabakaları görülmüş̧ür. Sürtünme tabakalarının oluşumu sürtünme performansı açısından önemlidir. Sürtünme tabakaları, balata yüzeyinde nispeten daha sert bölgelerdir ve uzun ömürlüdür. Fakat bir sebeple kırılması ve ayrışması halinde adezif aşınmaya sebep olabilir.

Balata ile disk arasına dışarıdan giren veya sürtünme esnasında malzemeden kopan cisim/partikül; eğer balatanın yüzeyine tekrar yapıştıktan sonra koparsa adezyon aşınması, eğer balatanın nispeten daha yumuşak bir bölgesini talaş kaldırma, yüzeyi kazıma gibi aşındırırsa abrazyon aşınması meydana gelir. Şekil 8'de numunelerin SEM resimlerinde görülen mikro boşluklar, meydana gelen adezyon aşınmasını ve ablativ aşınmayı göstermektedir. Ablativ aşınma, frenleme esnasında yükselen sıcaklığın etkisiyle fenolik reçinenin azalması ve dolgu partiküllerinin kopmasıdır. Sürtünme esnasında balata ile disk arasına giren tanecikler yüzey üzerinde bir akma/kayma davranışı da meydana getirir. Bu kayma davranışı daha yavaş bir aşınmaya sebep olur. Kayma ve abrazif aşınma arasındaki fark çok belirgin değildir [11].

\section{Sonuçlar}

$\mathrm{Bu}$ çalışmada, balata kompozisyonunu oluşturan malzemelerden aşındırıcıların (abraziflerin) miktarının fren balata performansına etkileri deneysel olarak incelenmiştir. Aşındırıcı olarak kütlece iki farklı miktarda (\%5 ve \%10) alümina, zirkon ve silika kullanılarak TS 555'e uygun 6 farklı balata numunesi üretilmiştir. Numuneyi oluşturan diğer içerikler oranlarıyla birlikte sabit tutulmuştur. Gerçekleştirilen testler ve analizlerden elde edilen sonuçlar aşağıda özetlenmişsir;

• Sürtünme testine tabi tutulan tüm numuneler arasında en yüksek sürtünme katsayısı 0.407 değeri, kütlece \%10 alümina içeren A10 kodlu numuneye, en düşük sürtünme katsayıs1 0.296 değeri ise kütlece $\% 5$ zirkon içeren Z5 kodlu numuneye aittir.

- Yapılan deneylerde aşındırıcı miktarı arttıkça sürtünme katsayısı ve sertliğin arttı̆̆ı, porozite oranının azaldığı görülmüştür. Ayrıca porozite oranı arttıkça özgül aşınma miktarının arttığı gözlemlenmiştir.

- Numunelerin mikroyapıları incelendiğinde sürtünme yüzeylerinde abrazif aşınmalar sonucu oluşan çizikler, mikro ve makro boşluklar ve adezif aşınmalar sonucu oluşan üzeri kaplanmış sürtünme tabakaları ile termo-mekanik gerilmelere bağlı olarak mikro çatlakların olduğu görülmüştür.

- Numunelerin testler sonucu elde edilen fiziksel özellikleri incelendiğinde yoğunluğun, porozite ile ters orantıll, sertlik ile doğru orantılı olduğu görülmüsştür. Ayrıca sertliği yüksek olan numunelerin ortalama sürtünme katsayısında artış 
görülürken özgül aşınma miktarında azalmalar görülmüştür. Yoğunluk ile porozite arasındaki ilişki literatür ile uyumludur.

- Sürtünme-aşınma testlerinden elde edilen sonuçların literatür ile uyumlu ve TS 555'e uygun olduğu görülmüştür.

\section{Kaynaklar}

[1] Bijwe, J.,Aranganathan, N., Sharma, S., Dureja, N., Kumar, R., "Nano-abrasives in frictionmaterials-influence on tribologicalproperties”Wear, 296(1), 693-701, 2012.

[2] Kim, S. S.,Hwang, H. J., Shin, M. W., Jang, H., "Frictionandvibration of automotivebrakepadscontainingdifferentabrasiveparticles”Wear, 271(7), 1194-1202, 2011.

[3] Shin, M. W., Kim, Y. H., Jang, H., "Effect of theabrasive size on thefrictioneffectivenessandinstability of brakefrictionmaterials: a casestudywithZircon”TribologyLetters, 55(3), 371-379, 2014.

[4] Ma, Y.,Martynková, G. S., Valášková, M., Matějka, V., Lu, Y., "Effects of $\mathrm{ZrSiO} 4$ in nonmetallicbrakefrictionmaterials on frictionperformance”Tribology International, 41(3), 166-174, 2008.

[5] Boz, M., Kurt, A., "Theeffect of Al2O3 on thefrictionperformance of automotivebrakefrictionmaterials”Tribology International, 40(7), 1161-1169, 2007.

[6] Ertan, R.,"Fren Balata Malzemelerinin Optimizasyonu ve Üretim Parametrelerinin Analizi” Uludağ Üniversitesi,Fen Bilimleri Enstitüsü Doktora Tezi, Bursa, 2008.

[7] TS 555 Karayolu Taşıtları-Fren Sistemleri-Balatalar-Sürtünmeli Frenler İçin, 1992.

[8] TS 9076 Karayolu Taşıtları-Fren Sistemleri-Fren Balataları-Malzeme Sürtünme Özelliklerinin Küçük Deney Parçaları ile Değerlendirilmesi, 1991.

[9] Sugözü, I.,“Investigation of usingricehuskdustandulexite in automotivebrakepads”MaterialsTesting, 57(10); 877-882, 2015.

[10] Hong, U. S.,Jung, S. L., Cho, K. H., Cho, M. H., Kim, S. J., Jang, H., "Wearmechanism of multiphasefrictionmaterialswithdifferentphenolicresinmatrices”Wear 266(7); 739-744, 2009.

[11] Sugözü, B.,Nano Silika, Nano Alümina ve Nano Zirkon Aşındırıcı Parçacık Katkısının Fren Balata Özelliklerine Etkisi, Selçuk Üniversitesi,Fen Bilimleri Enstitüsü Doktora Tezi, Konya, 2016.

[12] Persson, B. N. J.,“Theory of friction: The role of elasticity in boundarylubrication”, PhysicalReview B 50(7); 4771, 1994.

[13]Tabor, D.,"Friction as a dissipatedprocess. Friction of organicpolymers in fundamentals of friction”MacroscopicandMicroscopicProcesses 220(3); 1996.

[14] Moore, D. F.,“Principplessand Application Tribology”, In, Eds, Oxford: PergamonPress, p. 109-156, 1975.

[15] Anderson, A. E.,“ASM handbook, Friction, lubrication, andweartechnology” 18; 569-577, 1992.

[16] Stachowiak, G.W.,Batchelor, A.W., “EngineeringTribology”, Heineman, Boston, MA, pp. 36-44, 2001.

[17] Sasaki, Y.,“Proceedings of theFifthAkzoSymposium on Development of Non-asbestosfrictionmaterials”, 1986.

[18]Bijwe, J.,“Composites as friction materials: Recent developments in non-asbestos fiber reinforced friction materials - A review” Polymer Composites, 18 (3), 378-396, 1997. 


\section{Extended Abstract}

\section{Introduction}

The purpose of this research was to study the effects of abrasives on the friction and wear characteristics of automotive brake friction materials. Hence, six samples were developed using abrasives of three types (alumina, silica, zircon) and varying the size (5 wt\% and $10 \mathrm{wt} \%$ ). The hardness, density and porosity of the samples were measured. All samples were tested on a pad-on-disc type tester with grey cast iron disc to determine the tribological properties (according to TS 555). Detailed examinations on the worn surface were analyzed using a scanning electron microscopy.

\section{Method}

The content of the samples except the abrasives consists of phenolic resin as binder, steel wool as fiber, cashew, brass particles and copper particles as friction modifiers, graphite as solid lubricant and barite as space filler. The samples were produced by a conventional procedure for a dry formulation following dry-mixing, pre-forming and hot pressing. First, all components were weighed using a precision balance. The combinations were dry-mixed using a blender in order to achieve a homogeneous state ready for molding. Then the mixture was put into $25.4 \mathrm{~mm}$ diameter mold for pre-forming under $8000 \mathrm{kPa}$ at room temperature for $2 \mathrm{~min}$ and molded at $150{ }^{\circ} \mathrm{C}$ temperature in $10000 \mathrm{kPa}$ pressure for $12 \mathrm{~min}$. During the hot pressing process, pressure was released several times to release the gases that evolved from the cross linking reaction (polycondensation) of the phenolic resin.

Using a pad-on-disc type tester, friction tests were performed for each sample. For each sample, three friction test procedures were applied and the average of these three tests was recorded. The machine uses a pearlitic gray cast iron disc (diameter of $180 \mathrm{~mm}$, thickness $38 \mathrm{~mm}$ ) and a brake lining test sample with $25 \mathrm{~mm}$ diameter. The test sample was mounted on the load arm and pressed against the flat surface of the rotating disc. The rotating cast iron disc moved with a constant sliding speed of $\mathrm{v}=6 \mathrm{~m} / \mathrm{s}$ for 30 minutes and the temperature was increased from room temperature to around $100^{\circ} \mathrm{C}$. Before performing the testing, the surfaces of the test samples and the cast iron discs were ground with 320-grid sandpaper. The normal load was varied to achieve a constant friction force. The friction coefficient was calculated by measuring normal and tangential pressures every 5 seconds throughout the 30 minutes test. The weight and thickness of two pads and a disc for each sample were taken before and after the friction test. In order to obtain average thickness, six measurements (three at the beginning and three at the end) were taken at different locations on the pads and disc before and after the friction test. Wear rate was calculated as weight loss for per $\mathrm{mm}^{2}$ of the sample during the tests.

The brake lining composites were subjected to various physical tests. Density of the samples was calculated based on Archimedes principle. Porosity was obtained using a mercury porosimeter (AutoPore IV 9500). Hardness of the brake lining samples was measured by using Brinell hardness tester (62.5 kgf load and $2.5 \mathrm{~mm}$ steel ball).

\section{Results and Discussion}

Among all the samples subjected to the friction test, the highest coefficient of friction is 0.407 , the A10 code sample containing $10 \%$ alumina and the lowest coefficient of friction 0.296 is the sample code Z5 containing $5 \%$ zircon. As the amount of abrasive increased, friction coefficient and hardness increased and porosity ratio decreased. It is also observed that as the porosity ratio increases, the amount of specific wear increases. When the microstructures of the specimens are examined, it is seen that there are micro-fractures due to thermo-mechanical stresses and friction layers overlaid on the friction surfaces resulting in abrasive abrasions, micro and macro cavities and adhesive wears. When examining the physical properties of the samples resulting from the tests, it was found that the density was inversely proportional to porosity and directly proportional to the hardness. In addition, the average friction coefficient of samples with high hardness increased while the amount of specific wear decreased. The relationship between density and porosity is consistent with the literature. The results obtained from the friction-wear tests are in accordance with the literature and are found to comply with TS 555. 